\title{
THE
}

$12-9-2013$

\section{Processing of Underway CTD Data}

D. S. Ullman

University of Rhode Island, dullman@uri.edu

David Hebert

Follow this and additional works at: https://digitalcommons.uri.edu/gsofacpubs

Terms of Use

All rights reserved under copyright.

\section{Citation/Publisher Attribution}

Ullman, David S; Hebert, David. (2014). "Processing of Underway CTD Data." Journal of Atmospheric and Oceanic Technology. 31(4): 984-998.

Available at: http://dx.doi.org/10.1175/JTECH-D-13-00200.1

This Article is brought to you for free and open access by the Graduate School of Oceanography at DigitalCommons@URI. It has been accepted for inclusion in Graduate School of Oceanography Faculty Publications by an authorized administrator of DigitalCommons@URI. For more information, please contact digitalcommons-group@uri.edu. 


\title{
Processing of Underway CTD Data
}

\author{
DAVID S. ULLMAN \\ Graduate School of Oceanography, University of Rhode Island, Narragansett, Rhode Island \\ DAVID HEBERT \\ Bedford Institute of Oceanography, Fisheries and Oceans Canada, Dartmouth, Nova Scotia, Canada
}

(Manuscript received 20 September 2013, in final form 9 December 2013)

\begin{abstract}
A processing methodology for computation of accurate salinity from measurements with an underway CTD (UCTD) is presented. The UCTD is a rapidly profiling sensor package lacking a pump that relies on instrument motion to produce flow through the conductivity cell. With variable instrument descent rate, the flow through the cell is not constant, and this has important implications for the processing. As expected, the misalignment of the raw temperature and conductivity is found to be a function of the instrument descent rate. Application of a constant temporal advance of conductivity or temperature as is done with pumped CTDs is shown to produce unacceptable salinity spiking. With the descent rate of the UCTD reaching upwards of $4 \mathrm{dbar} \mathrm{s}^{-1}$, the effect of viscous heating of the thermistor is shown to produce a significant salinity error of up to $0.005 \mathrm{psu}$, and a correction based on previous laboratory work is applied. Correction of the error due to the thermal mass of the conductivity cell is achieved using a previously developed methodology with the correction parameters varying with instrument descent rate. Comparison of salinity from the UCTD with that from a standard shipboard, pumped CTD in side-by-side deployments indicates that the processed UCTD salinity is accurate to better than 0.01 psu.
\end{abstract}

\section{Introduction}

The Oceanscience underway CTD (UCTD) is a recently developed system for obtaining deep vertical profile CTD data from a moving ship (Rudnick and Klinke 2007). We recently used the UCTD on two hydrographic survey cruises as a means to increase the spatial resolution of the survey without having to perform additional time-consuming CTD casts. Examination of the UCTD data after preliminary processing, using standard methodologies, suggested that data quality was not ideal in situations where the instrument descent rate varied significantly. Since the UCTD is a nonpumped system, the flow through the temperature/conductivity (T/C) sensor duct varies with the descent rate, which is, in general, not constant. The variable flow through the sensor plumbing gives rise to a number of issues that complicate the processing of these data for computation

Corresponding author address: David S. Ullman, Graduate School of Oceanography, University of Rhode Island, 215 South Ferry Road, Narragansett, RI 02882.

E-mail: dullman@mail.uri.edu of salinity. These include flow dependence in the response times of temperature and conductivity sensors, in the time lag associated with the physical separation of the sensors, and in the effects of the thermal mass of the conductivity cell. In this paper, we describe the processing procedures that we have developed for improving the accuracy of salinity derived from the UCTD. The results are also likely to be useful for other applications in which unpumped CTD measurements are made, for example, autonomous gliders (Garau et al. 2011) or the Moving Vessel Profiler (Furlong et al. 2000).

The UCTD we used was similar to the prototype UCTD described by Rudnick and Klinke (2007), but with an upgraded winch system and the use of a custom-designed Sea-Bird Electronics (SBE) CTD using the same conductivity and temperature sensors used in its modular sensors (SBE-4 and SBE-3F). The UCTD is typically deployed by dropping it into the water vertically off the fantail of the moving ship. This is done with the system's winch in freespool mode; thus, line is paid out rapidly as the ship moves away from the deployment location. The UCTD can be deployed in two modes. In the free-cast mode, line is spooled onto the tail spindle prior to launch. 
This line pays out as the probe descends, as with an expendable bathythermograph (XBT), thus decoupling the instrument from the effects of the ship motion. The probe descends, in this case, at a rate of approximately $4 \mathrm{dbar} \mathrm{s}^{-1}$ until the line on the tail is fully paid out, at which time a rapid deceleration occurs (Fig. 1). There is, however, some variability in the probe descent rate, which becomes larger in amplitude as the line on the tail spool is depleted and the rapid deceleration point is approached. This is thought to arise from differences in the resistance to unwinding of the line from the tail spool as the line pays out from different parts of the tail spool. The second mode of deployment is the so-called tow-yo mode in which the probe is launched without winding line onto the tail. In this case, slack line is provided only by the freespool action of the winch. The probe fall rate in this case varies from approximately $3.5 \mathrm{dbar} \mathrm{s}^{-1}$ at the start to roughly $1 \mathrm{dbar} \mathrm{s}^{-1}$ at the deepest depth (Fig. 1).

Short-term spikes in salinity computed from raw conductivity and temperature measurements are a commonly encountered problem with CTD measurements. This has been shown by many prior investigations to be mainly due to misalignment of the temperature and conductivity measurements due to physical separation of the thermistor and the conductivity cell, as well as to mismatches between the response times of the two sensors (Horne and Toole 1980; Gregg and Hess 1985). With pumped CTD systems such as the commonly used SBE 911, where the flow through the T/C duct is constant, the proper alignment is easily achieved by advancing conductivity in time by a fixed amount. However, for unpumped CTDs, such as the UCTD, the flow through the conductivity cell is not constant, but varies with the instrument descent rate. If the descent rate does not vary much, as with the UCTD in free-cast mode, then the use of a constant advance value is justified, but in cases where the instrument descent rate varies widely, this approach is likely to fail.

Because of the large effect of temperature on the conductivity of seawater, the thermal mass of a CTD's conductivity cell can introduce errors in computed salinity on time scales of order $10 \mathrm{~s}$ when profiling in regions with vertical temperature gradients (Lueck 1990). This occurs because the heat lost or gained by the cell material changes the water temperature within the cell and thus its conductivity. Because the temperature sensor, typically smaller and located forward of the conductivity cell, is unaffected by this effect, the salinity computed using the measured conductivity will be in error. Lueck and Picklo (1990) developed a methodology to correct the measured conductivity for the thermal mass effect that greatly reduces the error in salinity. The magnitude and temporal response of the thermal mass error, and therefore the parameters of the correction algorithm, were predicted

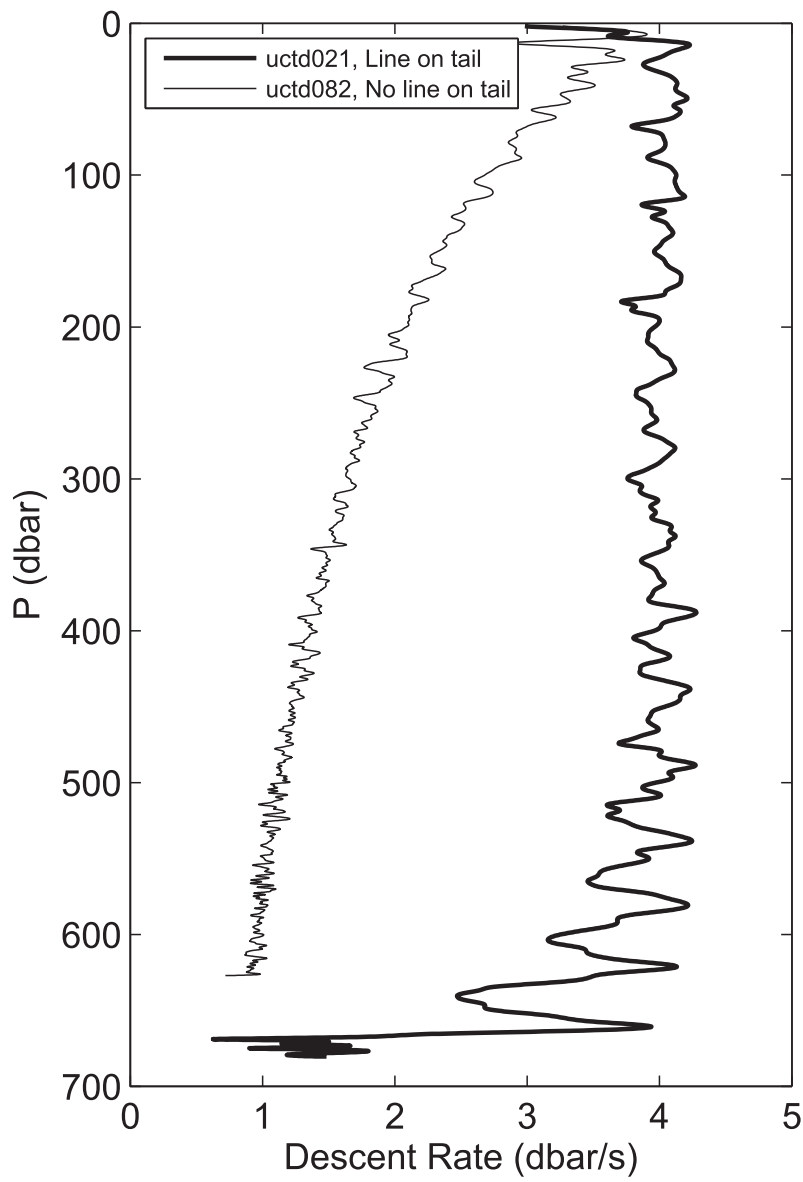

FIG. 1. Descent rate of the UCTD vs depth for a cast with line spooled on the tail (thick line) and for a cast with no line spooled on the tail (thin line).

theoretically to be dependent on the velocity through the conductivity cell (Lueck 1990) and this was subsequently confirmed using data from a number of field deployments (Morison et al. 1994). Whether the velocity-dependent functions of Morison et al. (1994) can be used for the UCTD is not clear a priori.

The measurement of temperature in flowing water with thermistors is subject to errors arising from the heating of the sensor itself due to viscous effects. This phenomenon was investigated by Larson and Pedersen (1996) using laboratory and numerical studies, finding that the error in temperature varies as the square of the water velocity. With a CTD, where salinity is computed from temperature measured by a thermistor along with a conductivity measurement that is not subject to such an error, the result of the viscous heating temperature error is an error in calculated salinity. For standard CTD measurements, the flow past the thermistor is of the order of $1 \mathrm{~m} \mathrm{~s}^{-1}$ and the temperature error is less than $1 \times 10^{-3}{ }^{\circ} \mathrm{C}$, which results in a negligible salinity error of 
less than $1 \times 10^{-3} \mathrm{psu}$. The quadratic dependence on velocity of the heating error suggests that the resulting salinity error could be significant for the rapidly profiling UCTD. A velocity of $4 \mathrm{~m} \mathrm{~s}^{-1}$ gives a temperature error of $4-5 \times 10^{-3}{ }^{\circ} \mathrm{C}$, resulting in a computed salinity error of 4 $5 \times 10^{-3}$ psu. Salinity errors of this magnitude can be significant in situations where the flow velocity changes rapidly, for example, the abrupt deceleration portion of a UCTD free cast (e.g., Fig. 1).

In this paper, we investigate the corrections necessary to produce accurate computations of salinity from UCTD measurements. We examine the short-term errors associated with the misalignment of the temperature and conductivity measurements, and the mismatch of the response time of the temperature and conductivity sensors for the case of variable flow past the sensors, both of which give rise to salinity spiking. We present evidence of velocitydependent salinity errors due to thermistor viscous heating errors in UCTD free casts and demonstrate that the empirical results of Larson and Pedersen (1996) are useful in correcting for this effect. Finally, we use test deployments of the UCTD on a CTD rosette package to optimize the conductivity thermal mass correction for the UCTD and examine the applicability of the Morison et al. (1994) functions for the correction parameters to the UCTD case.

\section{UCTD deployment and preliminary processing}

We deployed the UCTD on two cruises to the northwest corner region of the North Atlantic during the winter of 2011: Research Vessel (R/V) Knorr cruise KN200-02 and R/V Endeavor cruise EN492. Although it is possible to deploy the UCTD from a rapidly moving ship, in our case, since we were interested in increased profile depth, the ship was typically slowed to approximately 5-6 kt $\left(1 \mathrm{kt}=0.51 \mathrm{~m} \mathrm{~s}^{-1}\right)$ before deployment. The free-cast mode was our preferred deployment method, but because of occasional problems with the system that spools line onto the tail of the probe, we also deployed the system in tow-yo mode a number of times ( 22 of 81 casts on KN200-02 and 15 of 83 casts on EN492). When deployed in free-cast mode, where it is not possible to allow the UCTD to equilibrate to the temperature and conductivity conditions at the surface, we found it to be important to prewet the UCTD prior to launch. This was done by soaking the UCTD for roughly $15 \mathrm{~min}$ in a bucket supplied continuously from the running seawater systems of the research vessels. This procedure greatly reduced the incidence of large transients in conductivity and temperature in the upper $50 \mathrm{~m}$ of the profile that occurred if the UCTD was launched "dry" or after soaking in freshwater.

On both cruises, we performed one or more "calibration" casts wherein the UCTD was attached to the CTD rosette during a CTD cast in order to obtain side-by-side data with the highly accurate pumped SBE 911plus CTD used on these ships. The UCTD was mounted vertically with its intake $0.30-0.40 \mathrm{~m}$ above the CTD intake. This was not ideal in that we could not guarantee that the UCTD sampled "clean" water on descent due to the nearby presence of parts of the rosette structure, but this could not be avoided. The side-by-side comparison of the UCTD and the CTD was to some extent biased against the UCTD, which was not designed for the slow and highly variable descent rate of the CTD package when deployed in the typically rough seas encountered in the North Atlantic during winter. As will be shown below, the UCTD data in this case exhibit artifacts that are clearly correlated with profiling speed.

The UCTD samples temperature $T$, conductivity $C$, and pressure $P$ at $16 \mathrm{~Hz}$, thus providing nominal depth resolution of $0.25 \mathrm{dbar}$ when deployed in free-cast mode. The data are logged internally and are downloaded to a computer after recovery of the instrument. No processing is done internally. The temperature and conductivity measurements were low-pass filtered using a Butterworth filter with a cutoff period of $0.25 \mathrm{~s}$ (four scans). The filter was applied sequentially in the forward and the reverse directions to preserve phase information. The vertical velocity (descent rate) of the probe was computed from the measured pressure using a central difference scheme. The pressure and vertical velocity were also low-pass filtered, but with a filter cutoff period of $2 \mathrm{~s}$ in this case.

\section{Effects of variable descent rate}

Although originally envisioned as a way to calibrate the UCTD measurements against the more accurate CTD, the calibration casts provided a dataset that showed the performance of the UCTD under conditions of severe variability in the instrument descent rate. This included numerous instances of "looping," wherein the CTD package momentarily reverses direction. The UCTD is designed for downward profiling only, so it is no surprise that the UCTD data exhibited problems in this situation. But as Fig. 2 shows for one calibration cast, even when the descent rate remains positive (no looping), large salinity differences of $O(0.1 \mathrm{psu})$ are observed to coincide with periods of low descent rate. The salinity difference (UCTD minus CTD) is negative from 100 to $130 \mathrm{dbar}$, where the temperature increases with depth and is positive below $140 \mathrm{dbar}$, where the temperature gradient reverses. There is a mean salinity offset of opposite sign in each of these regions, which is likely an effect due to the thermal mass of the conductivity cell. This will be discussed further below. The large spikes in UCTD salinity are more puzzling. The sign of 

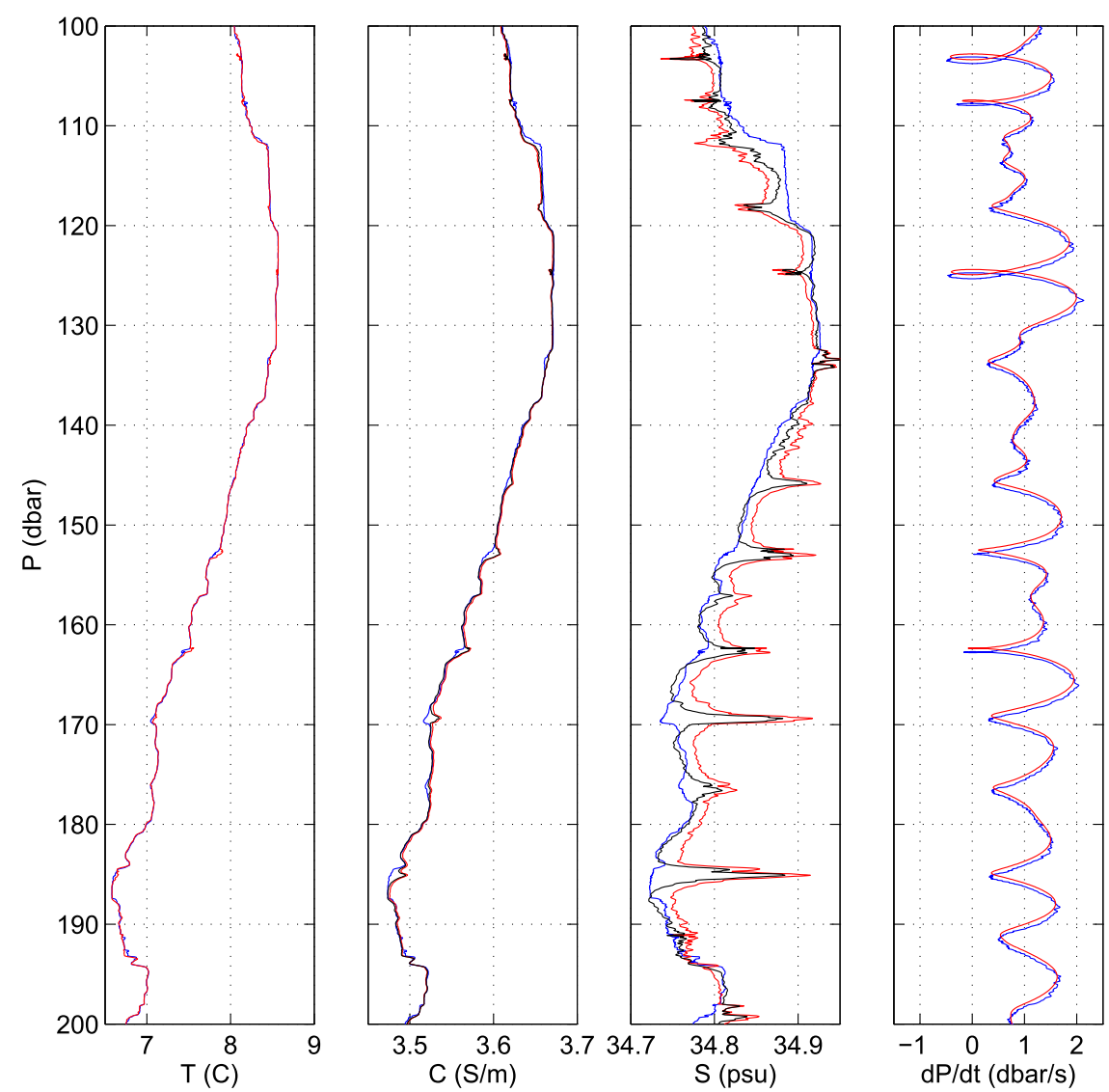

FIG. 2. Comparison between CTD (blue) and UCTD profiles (red and black) for a portion of a calibration cast during cruise KN200-02. The CTD data have been processed using standard SBE data processing methods. The red curves show UCTD data with a linear calibration applied to $T, C$, and $P$, but with no other processing. Shown are (left to right) $T, C, S$, and descent rate. The offset between the descent rate curves is due to the position of the UCTD pressure sensor approximately $0.35 \mathrm{~m}$ above the CTD pressure sensor. The black curves show the $C$ and $S$ after applying the full suite of processing, including alignment of $T$ and $C$, correction for thermistor viscous heating, and correction for the thermal mass of the conductivity cell.

the spikes is consistent with a misalignment of the UCTD temperature and conductivity measurements with temperature leading conductivity. However, application of reasonable lags to the temperature record (i.e., the descent-rate-dependent alignment discussed in section 4) does not eliminate these spikes. Closer examination of Fig. 2 indicates that the salinity spikes are coincident with peaks in the conductivity and temperature measurements, which suggest that water has been drawn down from several meters above the UCTD. It is possible that the UCTD is experiencing a wake effect from the CTD package, wherein the water in the wake of the CTD package overtakes the UCTD when the CTD package decelerates.

Although not apparent in all UCTD casts, in some cases when the UCTD descent rate changed rapidly we also observed salinity fluctuations, which appeared to be correlated with variations in the instrument descent rate.
This is shown in Fig. 3 for a portion of a UCTD cast where the descent rate varied from less than 1 to more than $4 \mathrm{dbar} \mathrm{s}^{-1}$. The increases in salinity, with a magnitude of $O(0.01)$ psu (an order of magnitude smaller than the fluctuations observed in the calibration casts), at approximately $577,607,634$, and 651 dbar all coincide with places where the descent rate decreased to around $1 \mathrm{dbar} \mathrm{s}^{-1}$. As will be discussed below, some of this variability could be a result of viscous heating of the thermistor, which can become significant at high descent rates.

\section{Processing methodologies}

\section{a. Alignment of temperature and conductivity}

\section{1) Descent-RATE-DEPENDENT ALignMENT}

Computation of salinity from the measured UCTD temperature, conductivity, and pressure can result in 

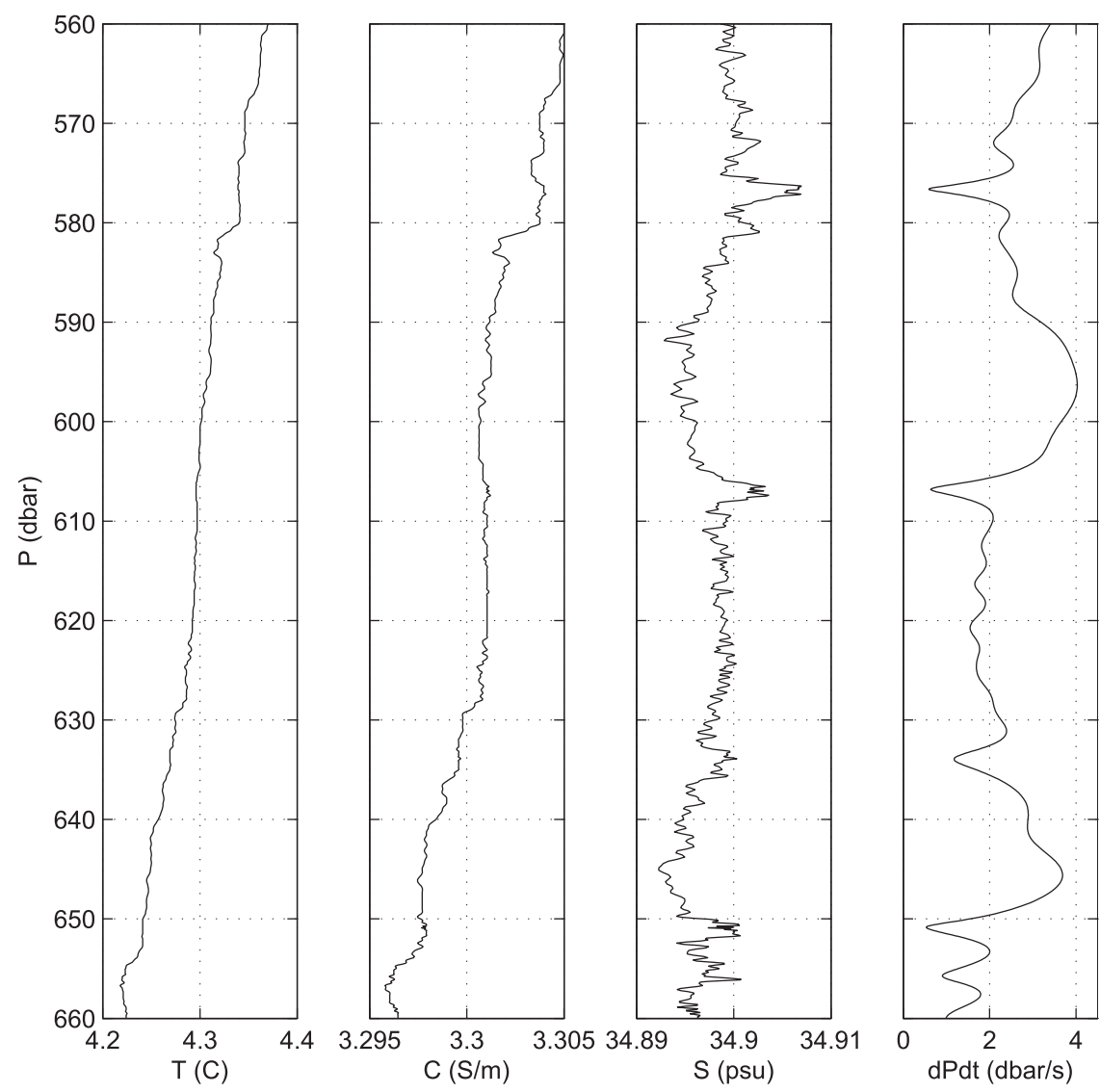

FIG. 3. UCTD cast 56 from EN492 showing a portion of the profile where the instrument descent rate exhibits large fluctuations: (left to right) $T, C, S$, and descent rate. The salinity was computed using $T$ and $C$ measurements that were filtered and aligned, but with no other corrections applied.

rather severe salinity spiking. For the prototype UCTD, Rudnick and Klinke (2007) found that advancing temperature by $0.1 \mathrm{~s}$ minimized salinity spiking. However, because the flow through the UCTD T/C duct is dependent on the instrument descent rate, which can be highly variable when deployed in tow-yo mode, a constant advance value is often not appropriate. This is shown for a typical tow-yo mode profile in Fig. 4, where severe spiking is observed for the case of no postprocessing advance (blue curve). Application of a constant advance of 1.29 scans (the appropriate value for a descent rate of $4 \mathrm{dbars}^{-1}$ as discussed below) to temperature improves the situation (black curve in Fig. 4), especially in the upper $100 \mathrm{~m}$ or so where the probe descent rate is high. However, there is significant spiking present in the lower half of the profile, especially in the 300-400-dbar range, where there is a large temperature gradient. In this part of the profile, the descent rate is much lower than the nominal $4 \mathrm{dbars}^{-1}$ that is achieved using the free-cast mode. The constant advance value used, which is appropriate for the high descent-rate part of the profile, results in larger salinity spikes than are present in the uncorrected profile in this region.

The optimal alignment of the temperature and conductivity measurements was determined empirically to depend on the descent rate of the UCTD probe. Using the methodology of Barth et al. (1996) for a towed CTD, for each 80 -scan $(5 \mathrm{~s})$ segment of data, the lag of $T$ relative to $C$ was determined as the lag at which the correlation between first-differenced temperature $\left(d T=T_{i+1}-T_{i}\right)$ and conductivity $\left(d C=C_{i+1}-C_{i}\right)$ was maximized. The precise value of the lag at maximum correlation was determined by finding the integer lag value (in scans) giving the highest correlation. The correlation at this point and those at lags 1 scan higher and lower were fit to a quadratic function of lag. The maximum of this function and the fractional lag at maximum correlation were then determined analytically. The resulting lag values, from all data segments from cruises KN200-02 and EN492, are shown as the 


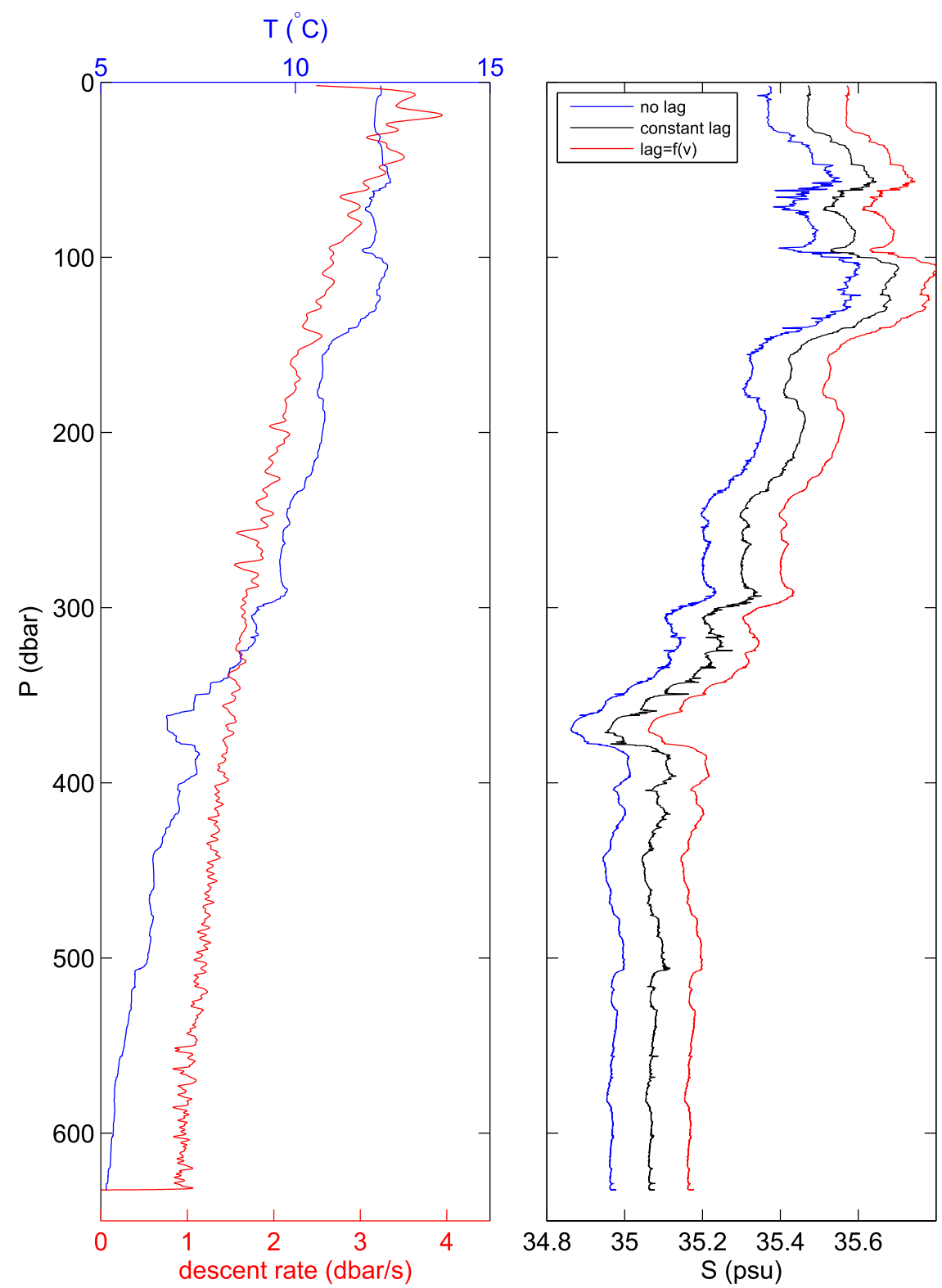

FIG. 4. Typical UCTD tow-yo mode profile exhibiting variable probe descent rate: (left) $T$ (blue) and descent rate (red) and (right) $S$ with no alignment of $T$ and $C$ (blue), alignment using a constant lag of 1.29 scans for $T$ (black), and with the lag of $T$ determined as a function of probe descent rate using the relation shown in Fig. 5 (red). The $S$ curves have been offset by 0.1 psu for clarity.

blue dots in Fig. 5 as a function of probe descent rate. At low descent rates $\left(d P / d t<\sim 1.25 \mathrm{dbar} \mathrm{s}^{-1}\right)$ temperature leads conductivity, while at high descent rates temperature lags conductivity. The lag data in Fig. 5 were averaged within bins of descent rate (with some outliers removed) to obtain the red curve in Fig. 5. At the $4 \mathrm{dbar} \mathrm{s}^{-1}$ descent rate achieved during free casts, temperature lags conductivity by 1.29 scans $(0.0808 \mathrm{~s})$, thus requiring temperature to be advanced by this amount to properly align $T$ and $C$.
This advance value is slightly less than the value determined by Rudnick and Klinke (2007) for the prototype UCTD. The averaged curve from Fig. 5 was used to align the UCTD temperature with conductivity, with the advance (lag) at a given time dependent on the local descent rate of the probe. The red curve in Fig. 4 shows that the salinity computed using $T$ and $C$ aligned using this method exhibits less spiking than the profile computed using a constant advance. 


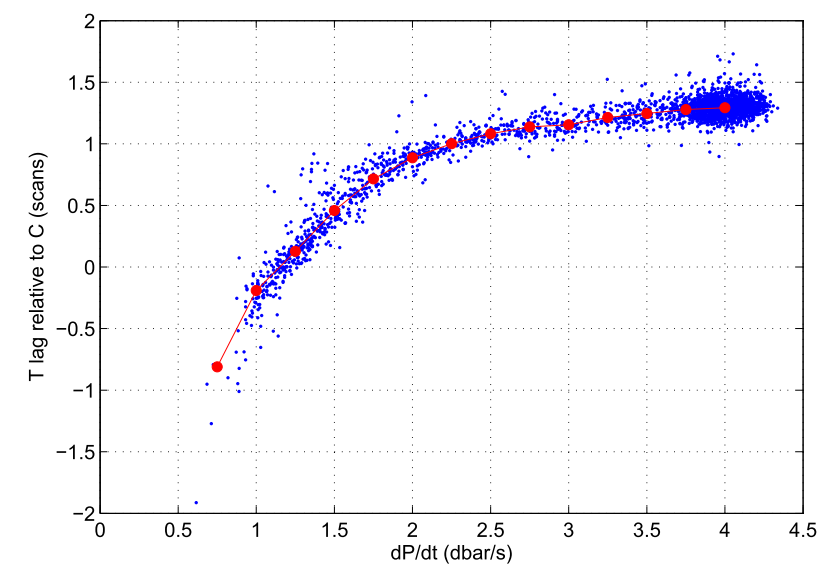

FIG. 5. Lag, in scans $(1 \mathrm{scan}=0.0625 \mathrm{~s})$, of $T$ relative to $C$ as a function of average probe descent rate over 80 -scan segments. Positive lag is defined as $T$ lagging $C$. The blue dots are the lag values determined from the individual 80 -scan segments, and the red dots are averages within $0.25 \mathrm{dbar} \mathrm{s}^{-1}$ bins with outliers removed.

\section{2) Modeling LAG BeHAVIOR}

As shown in Fig. 6, the UCTD draws in water at the tip of the nose cone through a tube with an approximate radius of $0.3 \mathrm{~cm}$. The water flows past the thermistor, located just inside the intake, then through the conductivity cell [radius of $0.2 \mathrm{~cm}$ according to Lueck (1990)], and finally exits through ports on the side of the probe body. The flow through the internal path will be reduced from the free-stream value (probe descent rate). The flow velocity through the probe is estimated using an assumption of steady, laminar pipe flow. From Kundu (1990, p. 271):

$$
u_{2}=\frac{a^{2}}{8 \rho \nu} \frac{\partial P}{\partial x}=\frac{a^{2}}{8 \rho \nu} \frac{\left(P_{2}-P_{1}\right)}{l}
$$

where $a$ is the tube radius, $\rho$ is the fluid density, $\nu$ is the fluid kinematic viscosity, $l$ is the length of the tube between the inlet and outlet, and $P_{2}$ and $P_{1}$ are the pressures at the inlet and outlet, respectively. The inlet and outlet pressures and velocities are related using the Bernoulli equation:

$$
P_{1}+\frac{1}{2} \rho u_{1}^{2}=P_{2}+\frac{1}{2} \rho u_{2}^{2}
$$

where the subscripts 1 and 2 refer to the outlet (free stream) and inlet values, respectively. Combining Eqs. (1) and (2) and solving the resulting quadratic equation for $u_{2}$, the velocity at the inlet of the tube (and assumed uniform throughout the tube length) gives

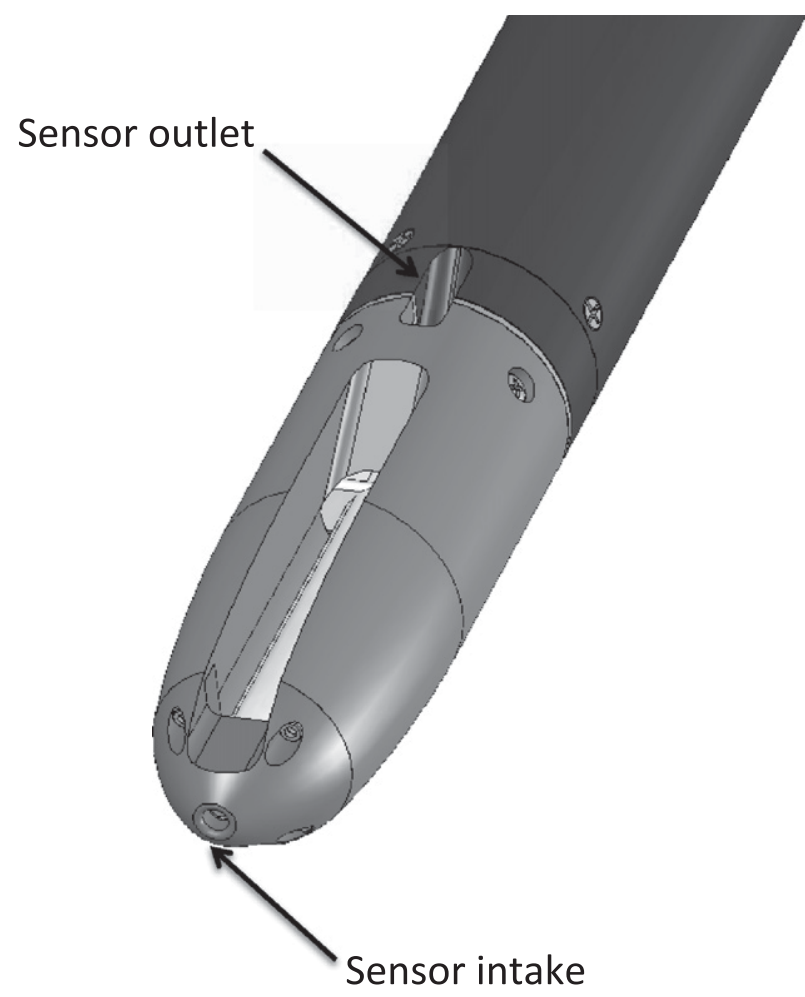

FIG. 6. Schematic of the UCTD probe section.

$$
u_{2}=\frac{-8 \nu l+\sqrt{(8 \nu l)^{2}+a^{4} u_{1}^{2}}}{a^{2}} .
$$

Using values $a=2 \times 10^{-3} \mathrm{~m}, l=0.17 \mathrm{~m}$, and $\nu=1.36 \times$ $10^{-6} \mathrm{~m}^{2} \mathrm{~s}^{-1}$, with a free-stream velocity $u_{1}=1 \mathrm{~m} \mathrm{~s}^{-1}$ gives $u_{2}=0.635 \mathrm{~m} \mathrm{~s}^{-1}$ ( $63.5 \%$ of the free-stream value). With the free-stream velocity $u_{1}=4 \mathrm{~m} \mathrm{~s}^{-1}$, we get $u_{2}=$ $3.56 \mathrm{~m} \mathrm{~s}^{-1}$ ( $89.0 \%$ of the free-stream value).

The response time of the UCTD temperature sensor (the same sensor used in an SBE-3F), defined as the time to reach $63 \%$ of the final value following a step change in temperature, is given by SBE as $0.070 \mathrm{~s}$ at $0.5 \mathrm{~m} \mathrm{~s}^{-1}$ flow rate and $0.065 \mathrm{~s}$ at $1.0 \mathrm{~m} \mathrm{~s}^{-1}$ flow rate. Because of the large mass of the UCTD probe, it seems likely that these values will be lower bounds and that the response time could be much larger. Following Johnson et al. (2007), we propose a simple model for the velocity dependence of the thermistor response time as

$$
\tau_{T}=c_{0}+\frac{c_{1}}{u_{2}}
$$

where $c_{0}$ and $c_{1}$ are constants to be determined and $u_{2}$ is the water velocity past the thermistor (assumed equal to the velocity through the conductivity cell). 
The response time of the SBE conductivity sensor is dependent on the time to flush the conductivity cell. Following Perkin and Lewis (1982), we define the response time analogously to the thermistor time constant as the time to reach $63 \%$ of the final value in response to a step change in conductivity:

$$
\tau_{C}=-0.63 \frac{L_{\text {cell }}}{u_{2}}
$$

where $L_{\text {cell }}$ is the length of the conductivity cell $(0.11 \mathrm{~m}$ according to Lueck 1990) and the negative sign indicates that $T$ leads $C$ due to this effect.

The placement of the thermistor just inside the probe inlet, upstream of the conductivity cell, will also produce a negative lag (lead) of $T$ relative to $C$ that is proportional to the distance between the sensors and inversely proportional to the water velocity through the probe:

$$
\tau_{\text {sep }}=-\frac{\Delta x}{u_{2}}
$$

where $\Delta x$ is the distance from the thermistor to the entrance of the conductivity cell, estimated as $0.021 \mathrm{~m}$.

The lag of $T$ relative to $C$ results from the sum of contributions due to the sensor response times and the physical displacement of the sensors. Summing Eqs. (4)(6) gives

$\tau_{\text {total }}=\tau_{T}+\tau_{C}+\tau_{\text {sep }}=c_{0}+\frac{c_{1}}{u_{2}}-\frac{0.63 L_{\text {cell }}+\Delta x}{u_{2}}$.

The constants $c_{0}$ and $c_{1}$ were determined by fitting the model, using least squares, to the empirical data of lag versus velocity (Fig. 5) with the descent rate, $u_{1}=\partial P / \partial t$, and the velocity through the probe related through (3). This procedure results in estimates of $c_{0}=0.0967 \mathrm{~s}$ and $c_{1}=0.0246 \mathrm{~m}$. The resulting curve is shown by the solid black line in Fig. 7.

The thermistor response time, given by (4) using the estimates derived above for the constants $c_{0}$ and $c_{1}$, is $\tau_{T}=0.1213 \mathrm{~s}$ evaluated at a velocity of $1 \mathrm{~m} \mathrm{~s}^{-1}$. This is roughly a factor of 2 larger than the SBE estimate for the response time given above. If we were to compute $c_{0}$ and $c_{1}$ such that the thermistor response times equal the SBE estimates at 0.5 and $1.0 \mathrm{~m} \mathrm{~s}^{-1}$, then the resulting model of the temperature lag is shown by the dashed line in Fig. 7. This model underestimates the lag of $T$ relative to $C$, suggesting that the actual thermistor response time in the UCTD is longer than the nominal values. The analysis above assumed laminar flow in the probe sensor duct. The calculation of the velocity within the duct was repeated assuming turbulent pipe flow and the result

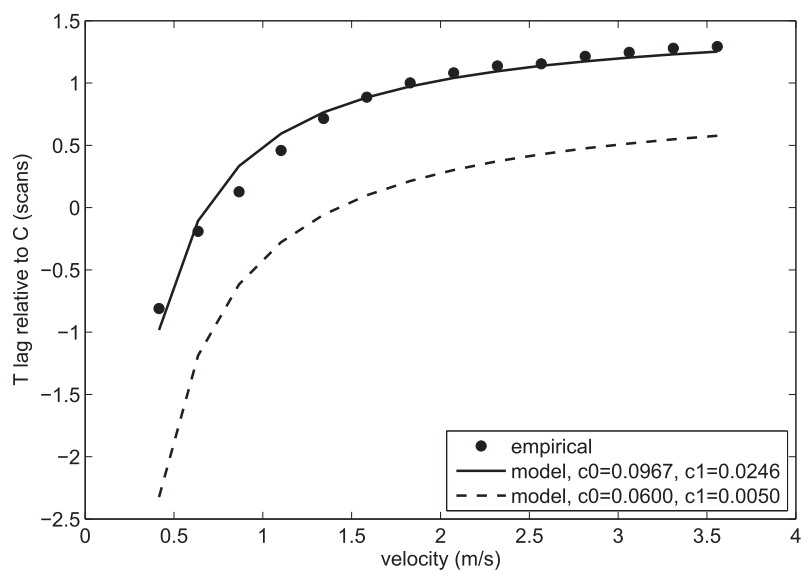

FIG. 7. Lag, in scans $(1 \mathrm{scan}=0.0625 \mathrm{~s})$, of $T$ relative to $C$ as a function of velocity through the probe sensor tube [estimated from the descent rate using Eq. (3)]. Positive lag is defined as $T$ lagging $C$. The black dots are the bin-averaged lag values from Fig. 5, the solid curve is the model with constants $c_{0}$ and $c_{1}$ estimated to fit the observations, and the dashed curve is the model with constants $c_{0}$ and $c_{1}$ computed to be consistent with the SBE estimate of the thermistor time constant.

(not shown) is qualitatively similar to the result presented here.

\section{b. Accounting for thermistor viscous heating}

When the UCTD is deployed in free-cast mode, the descent rate is roughly $4 \mathrm{dbar} \mathrm{s}^{-1}$ but with large oscillations often superimposed, especially as the amount of line remaining on the tail spool gets low. When the spooled line on the tail is all paid out, the probe decelerates rapidly (Fig. 1). Examination of temperature and derived salinity profiles in the region of rapid deceleration showed that in many such cases (e.g., Fig. 3), a salinity jump of $O(0.01 \mathrm{psu})$ without a corresponding temperature change occurred as the probe decelerated. It appeared that salinity varied with descent rate. This is shown statistically by plotting salinity variation as a function of descent rate for the high deceleration region $( \pm 50 \mathrm{dbar}$ from the location of highest deceleration) of all free-cast mode casts. We restrict the analysis to those casts reaching at least $500 \mathrm{dbar}$ for which the conductivity variance is small (low variations of $T$ and $S$ ). Figure 8a clearly indicates a negative correlation between salinity and descent rate. For descent rates $>1.5 \mathrm{dbar} \mathrm{s}^{-1}$, the correlation coefficient between salinity anomaly and descent rate of -0.28 is significantly different from zero at the $95 \%$ level.

We hypothesize that the negative correlation between salinity and descent rate might result from viscous heating of the thermistor as described by Larson and Pedersen (1996). Using the steady-state results of Larson and 
(a). Salinity Anomaly vs. Descent Rate without Viscous Heating Correction
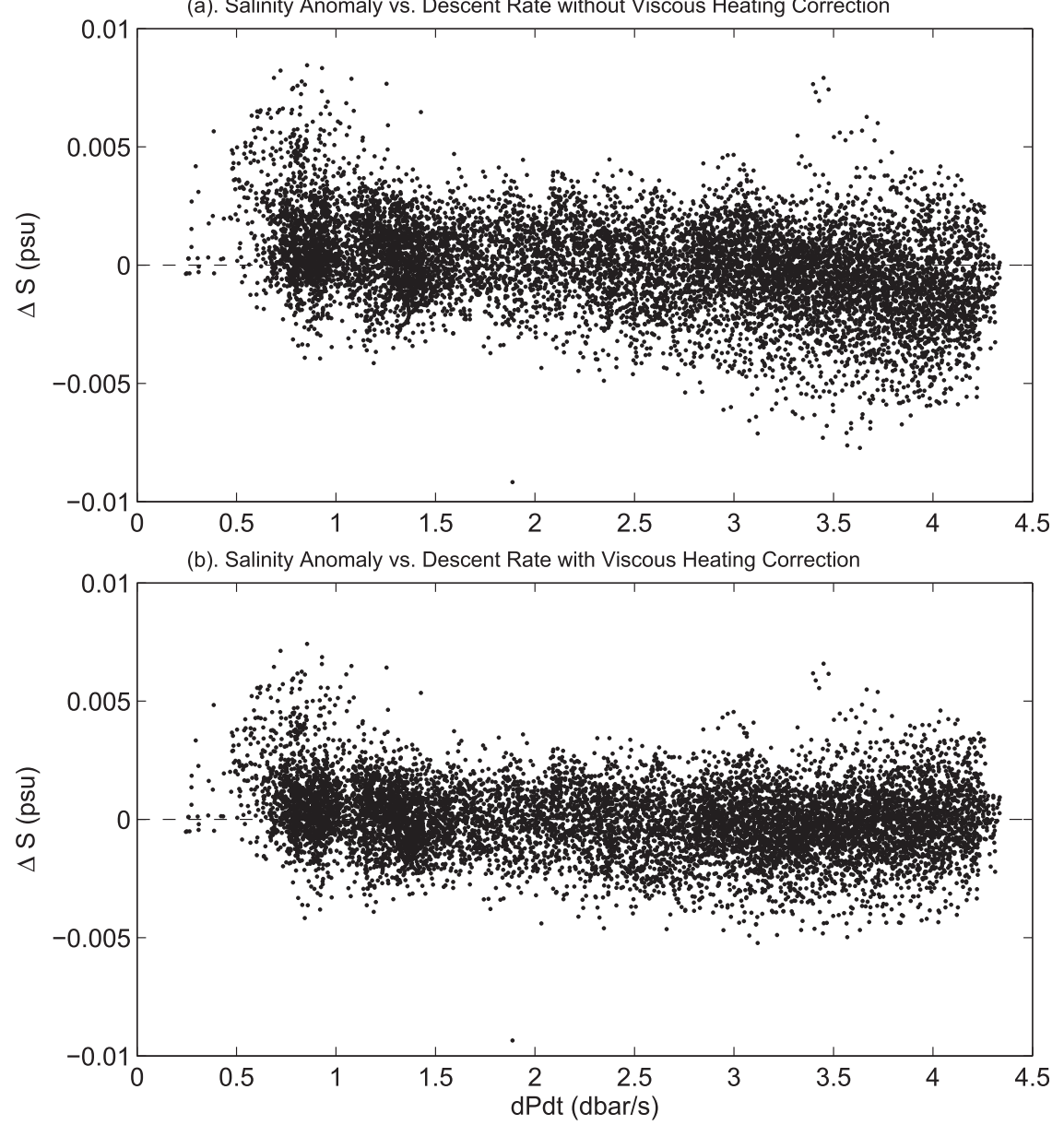

FIG. 8. Salinity anomaly, the difference between $S$ and the least squares linear fit to $S$ as a function of depth vs probe descent rate for the case (a) without viscous heating correction and (b) with the viscous heating correction applied. Data are from a total of 26 free casts where temperature did not deviate by more than $0.05^{\circ} \mathrm{C}$ from the linear fit to temperature from the region $\pm 50 \mathrm{dbar}$ from the maximum deceleration point of the cast.

Pederson for the perpendicular flow case, which most closely approximates the UCTD situation, we computed the viscous heating effect as

$$
d T=0.80 \times 10^{-4} \operatorname{Pr}^{0.5} v^{2},
$$

where Pr is the Prandtl number and $v=\partial P / \partial t$ is the (variable) probe descent rate. If the measured temperature is corrected by subtracting the viscous heating effect given by (8) prior to the computation of salinity, the correlation between salinity and descent rate that is apparent in Fig. 8a, for descent rates $>1.5 \mathrm{dbar} \mathrm{s}^{-1}$, disappears (Fig. 8b).

An example showing the effect of the viscous heating correction is given in Fig. 9, where the uncorrected salinity is observed to abruptly increase by nearly $0.01 \mathrm{psu}$ when the probe slows down. The salinity computed from the corrected temperature $\left(T_{\text {corr }}=T-d T\right)$ and the measured conductivity (red curve in Fig. 9, third plot from left) is thus shifted higher during periods of rapid probe descent (above about $680 \mathrm{dbar}$ in the example shown in Fig. 9). This has the effect of reducing the abrupt increase in computed salinity that is evident using the uncorrected temperature. However, the viscous heating correction appears to be insufficient to explain the full magnitude of the salinity jump, suggesting that either the correction is underestimated or that some other process is at work.

\section{c. Conductivity cell thermal mass correction}

The CTD-UCTD comparison shown in Fig. 2 indicates that the raw UCTD salinity is low (high) relative to the processed CTD salinity in regions where the temperature increases (decreases) with depth. This behavior is consistent 

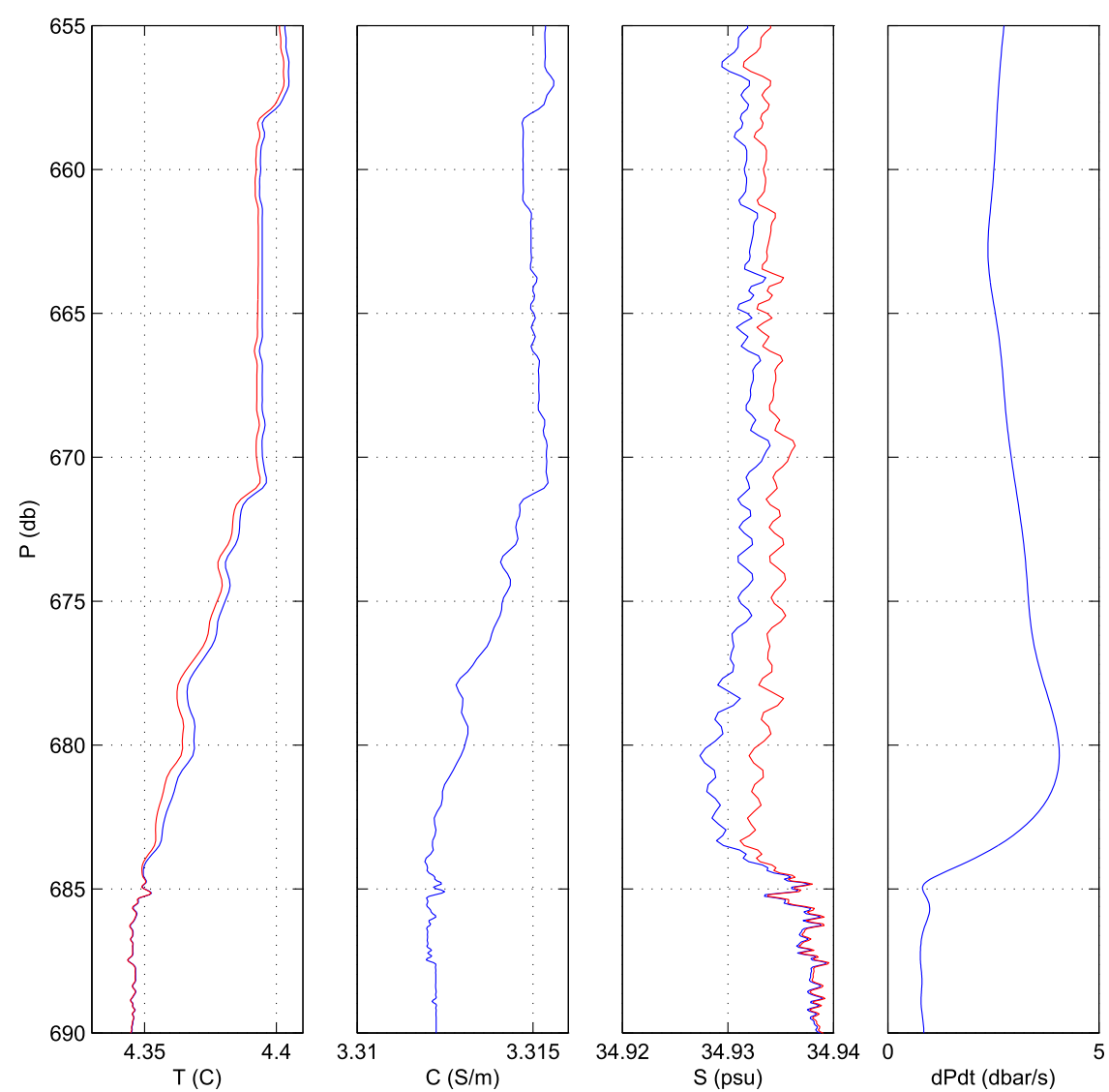

FIG. 9. Portion of UCTD cast 016 from EN492, showing (left to right) $T, C, S$, and descent rate. The blue $T$ and $S$ curves are the raw $T$ and the $S$ computed from this temperature. Note the jump in $S$ (blue curve) at about 683 dbar corresponding to the probe deceleration. The red curves are the $T$ corrected for viscous heating and the $S$ computed from the corrected temperature.

with the expected effect of a UCTD conductivity cell thermal mass error (Lueck 1990). We used the calibration casts to optimize a cell thermal mass correction of the type proposed by Lueck and Picklo (1990).

The parameters controlling the Lueck and Picklo (1990) thermal mass correction algorithm, the magnitude of the error $\alpha$ and the time constant of the error $\tau$, were determined for each calibration cast by finding the values that minimized the root-mean-square (rms) difference between the thermal-mass-corrected UCTD salinity and the CTD salinity. To avoid inclusion of the UCTD salinity spikes at low descent rates, the rms difference was computed using only those portions of the profile for which the descent rate exceeded $1.5 \mathrm{dbar} \mathrm{s}^{-1}$. Because a simple calibration error could produce an offset of the UCTD salinity relative to the CTD salinity, similar to that produced by the thermal mass error, we also performed a linear calibration of the UCTD temperature and conductivity using the CTD values as the true values. Separate calibrations were performed for each of the two
UCTDs on each of the two cruises. The calibrations used only observations within manually selected depth ranges that were nearly isothermal and thus are expected to have minimal effects of conductivity cell thermal mass errors. The calibrated UCTD data were processed using the filtering, aligning, and viscous heating corrections described above along with the thermal mass correction for different combinations of $\alpha$ and $\tau$. For all calibration casts, plots of the rms salinity difference (UCTD minus CTD) versus $\alpha$ and $\tau$ (e.g., Fig. 10) show a clear minimum, albeit one that is somewhat poorly defined along lines of roughly constant $\alpha \times \tau$. The $\alpha$ and $\tau$ values corresponding to the minimum rms error were taken to represent the optimum values for the thermal mass correction.

The results of the optimization of the conductivity cell thermal mass correction are given in Table 1 for all calibration casts. The rms salinity errors using the optimum thermal mass correction parameters range from 3-8 $\times$ $10^{-3}$. Because the calibration casts were done with the UCTD clamped to the CTD rosette that was lowered at 


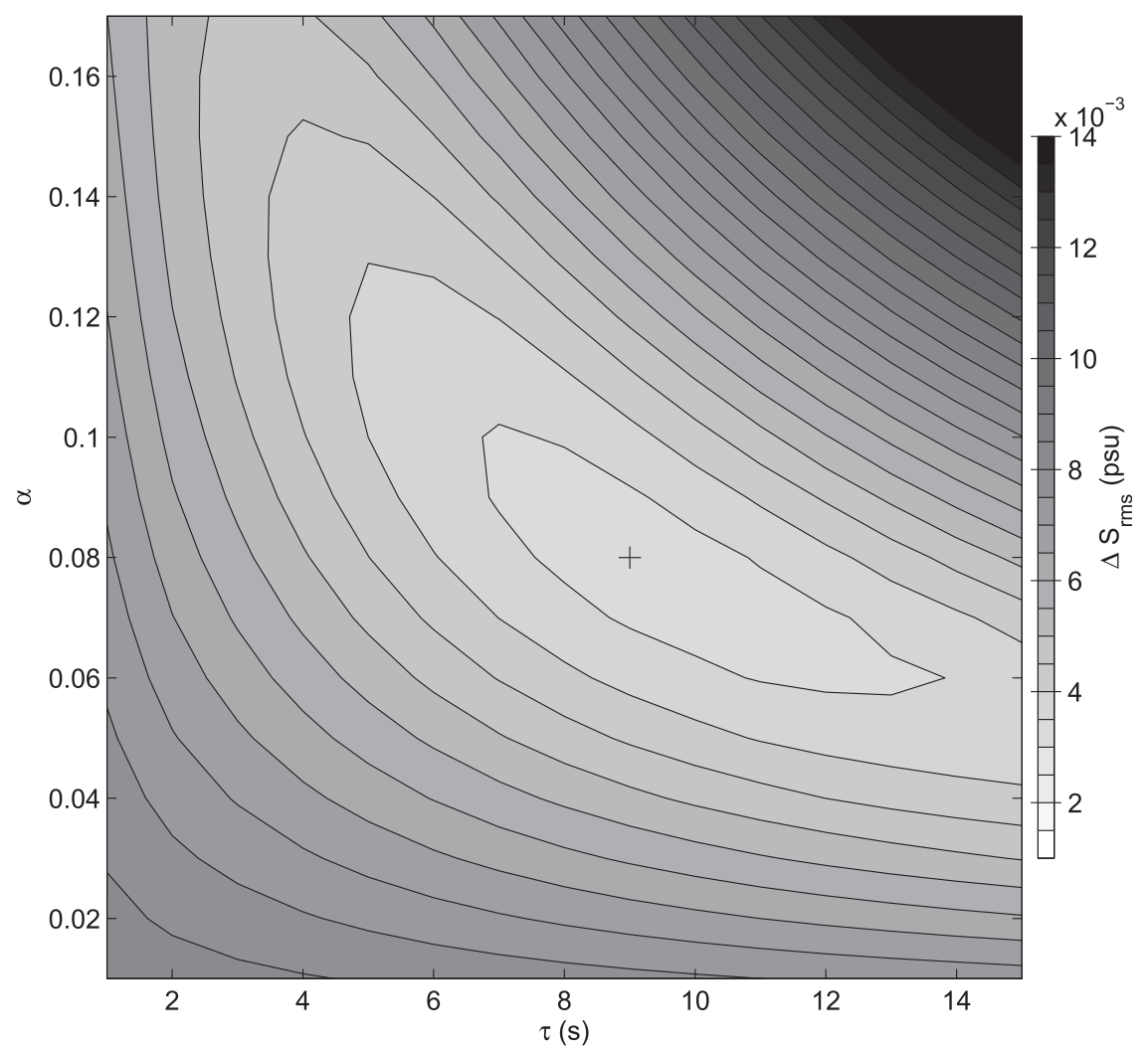

FIG. 10. RMS difference between UCTD and CTD salinity for one calibration cast, computed only at depths where the descent rate exceeds $1.5 \mathrm{dbar} \mathrm{s}^{-1}$, as a function of the parameters $\alpha$ and $\tau$, of the thermal mass error. The location of minimum error $\left(3.3 \times 10^{-3} \mathrm{psu}\right)$ is denoted by the plus symbol.

standard rates $\left(0.5 \mathrm{dbars}^{-1}\right.$ in the upper $100 \mathrm{~m}$ and $1 \mathrm{dbar} \mathrm{s}^{-1}$ thereafter), there is not much variation among the different casts in the mean descent rate or in the estimate of the velocity through the UCTD conductivity cell. Nonetheless, we plot the optimum thermal mass correction parameters along with the Morison et al. (1994) velocity-dependent functions (for an SBE conductivity cell) in Fig. 11. Averaging over all calibration casts, the mean values are $\alpha=0.10$ and $\tau=7.8 \mathrm{~s}$. The mean $\alpha$ is about $57 \%$ higher and the mean $\tau$ is $23 \%$ lower than the corresponding Morison et al. (1994) function values evaluated at the mean velocity.

The effect of the cell thermal mass correction can be seen in Fig. 2, where the salinity computed using the optimal thermal mass correction along with the alignment and viscous heating corrections (black curves in Fig. 2) agrees quite well with the CTD-derived salinity when the descent rate is greater than $1.5 \mathrm{dbar} \mathrm{s}^{-1}$. Note

TABLE 1. Results of the optimization of the UCTD conductivity cell thermal mass correction. The mean descent rate $\left(\partial P / \partial t_{\text {mean }}\right)$ was computed neglecting negative values. The velocity through the conductivity cell (vcell ${ }_{\text {mean }}$ ) was estimated using (3). S/N represents serial number below.

\begin{tabular}{lccccrrr}
\hline \hline Cruise & CTD cast & UCTD S/N & $\partial P / \partial t_{\text {mean }}\left(\mathrm{dbar} \mathrm{s}^{-1}\right)$ & vcell $_{\text {mean }}\left(\mathrm{m} \mathrm{s}^{-1}\right)$ & $\alpha$ & $\tau(\mathrm{s})$ & $\Delta S_{\text {rms }}(\mathrm{psu})$ \\
\hline KN200-02 & 056 & 0061 & 0.90 & 0.55 & 0.54 & 0.14 & 4 \\
KN200-02 & 057 & 0060 & 0.89 & 0.90 & 0.55 & 0.13 & 6 \\
KN200-02 & 099 & 0060 & 0.90 & 0.55 & 0.06 & 12 & $3.2 \times 10^{-3}$ \\
KN200-02 & 099 & 0061 & 0.88 & 0.53 & 0.08 & 9 \\
EN492 & 033 & 0061 & 0.88 & 0.53 & 0.07 & 7 & $3.3 \times 10^{-3}$ \\
EN492 & 033 & 0060 & 0.89 & 0.54 & 0.11 & 9 \\
Mean & & & & & 0.10 & 7.8 & $4.4 \times 10^{-3}$ \\
\hline
\end{tabular}


(a). Thermal Mass Error Magnitude

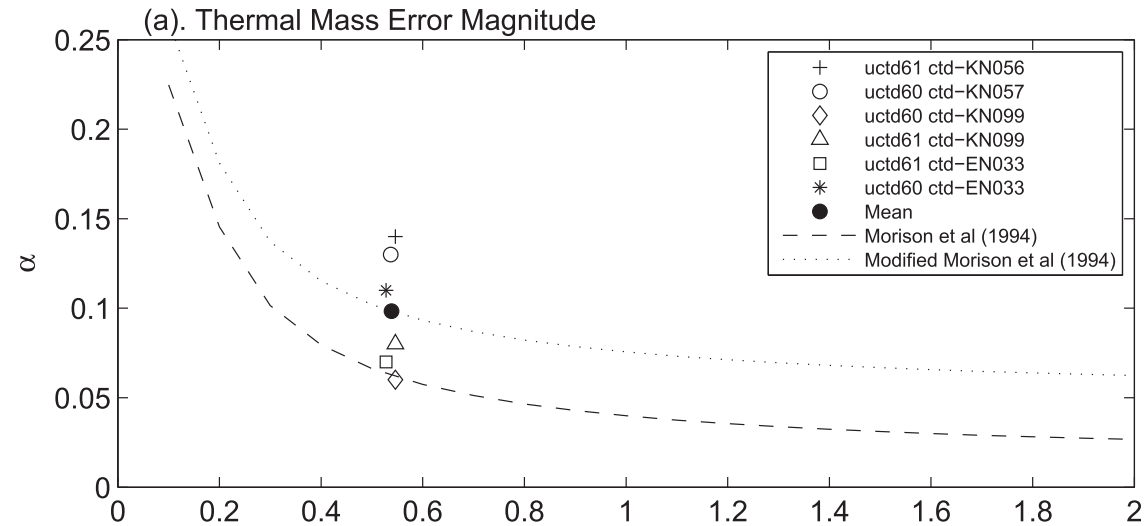

(b). Thermal Mass Error Time Constant

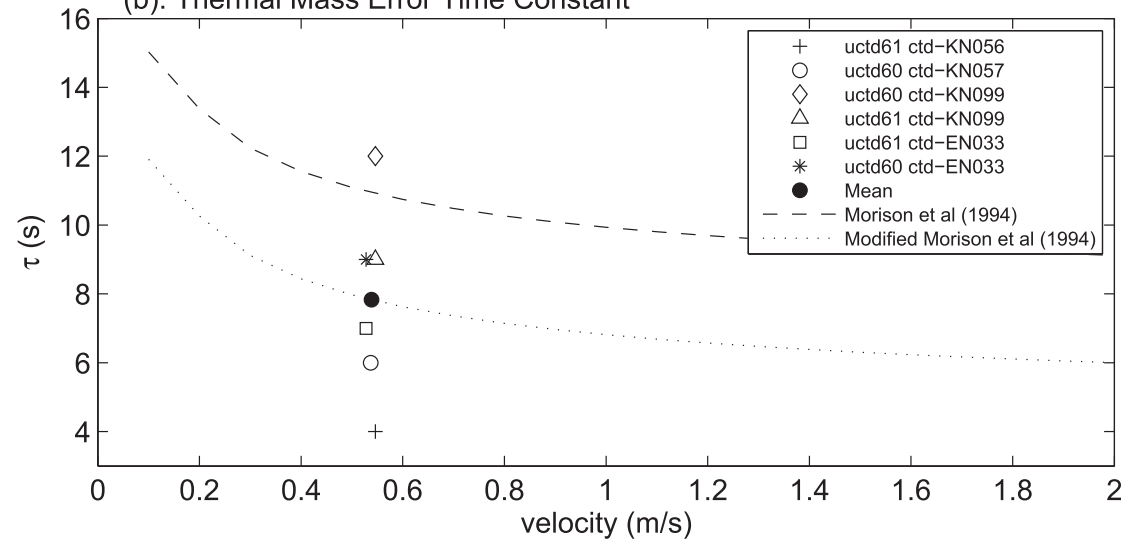

FIG. 11. (a). Parameter $\alpha$ vs estimated velocity through UCTD conductivity cell for each comparison CTD cast. (b). Parameter $\tau$ vs velocity. The mean for each parameter is given by the solid black circle. The dashed curve in each plot is the velocity-dependent function of Morison et al. (1994) for the SBE conductivity cell. The dotted curves show the Morison et al. (1994) functions, modified to pass through the mean values.

that at descent rates characteristic of the CTD casts $\left(\leq 2 \mathrm{dbar} \mathrm{s}^{-1}\right)$, the alignment and viscous heating corrections to the UCTD data are both small.

The magnitude of the conductivity cell thermal mass correction is known to depend on the flow rate through the cell (Lueck 1990; Morison et al. 1994). This raises the question of how to correct for thermal mass error in real UCTD casts where the descent rate is generally much larger than the $\sim 1 \mathrm{dbars}^{-1}$ CTD lowering rate of the calibration casts. We experimented with several approaches and evaluated the performance by visually examining all UCTD profiles, looking carefully at locations where the UCTD passed from a temperature gradient into an isothermal region. We compared uncorrected profiles and those corrected for thermal mass errors using (i) constant parameters equal to the average values discussed above, (ii) velocity-dependent parameters using the Morison et al. (1994) functions, and (iii) velocitydependent parameters from a modification of the Morison et al. (1994) functions to pass through the average values by adjusting the constant terms (dotted curves in Fig. 11).

Application of a thermal mass correction using the constant average values for the parameters was clearly not appropriate in general. For free casts in particular, with descent rates of $\sim 4 \mathrm{dbar} \mathrm{s}^{-1}$, the use of these parameters resulted in overcorrection, often producing obviously spurious density inversions. This was also the case for thermal mass corrections using the modifed Morison et al. (1994) functions. In fact, for free casts, even the reduced magnitude of the correction provided by the Morison et al. (1994) formulations proved to be slightly too much on occasion. For portions of free casts with descent rates $>\sim 3.5 \mathrm{dbar} \mathrm{s}^{-1}$, thermal mass errors appear to be small enough to be neglected and no correction seems to be the best approach. For tow-yo mode casts with a variable instrument descent rate, use of the Morison et al. (1994) velocity-dependent correction parameters produced the best results, with the modified Morison et al. (1994) parameters slightly overcorrecting in some instances. 
(a). Temperature
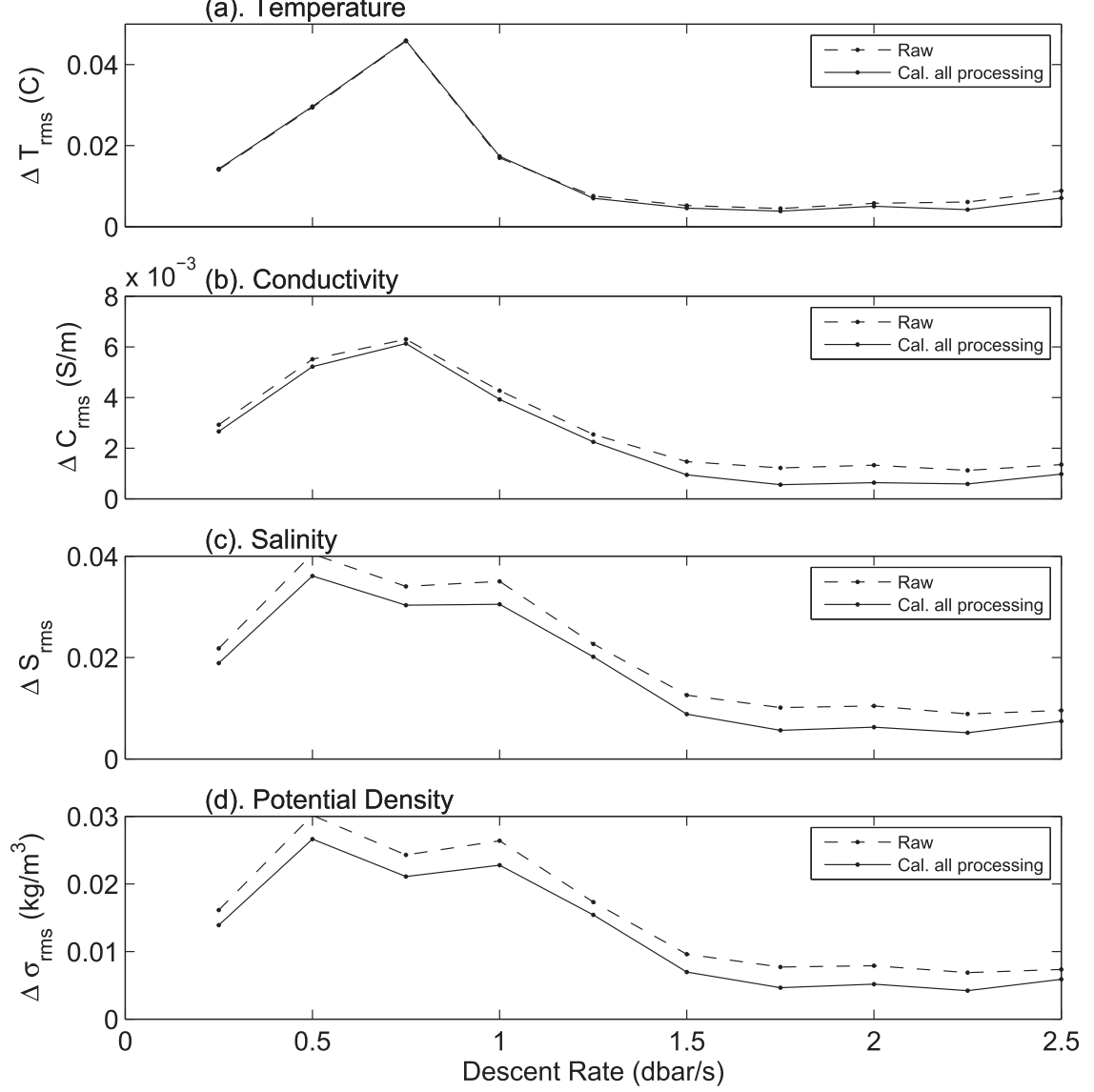

FIG. 12. The rms differences in (a) $T$, (b) $C$, (c) $S$, and (d) potential density for raw (dashed lines) and calibrated/processed (solid lines) UCTD measurements relative to CTD values as a function of instrument descent rate averaged over all calibration casts. The UCTD and CTD data were bin averaged into 0.5 -dbar bins.

\section{Discussion}

An important issue regarding hydrographic observations from the UCTD is their accuracy. For salinity, to some extent, this can be gleaned from Table 1, but the rms values reported there are associated with the optimized thermal mass correction for each individual calibration cast. More representative estimates are obtained by computing error statistics with UCTD data processed in a uniform manner. The processing steps outlined previously, using velocity-dependent thermal mass correction parameters from the Morison et al. (1994) functions, were applied to the UCTD data from the six calibration CTD casts (treating each UCTD-CTD comparison as a separate cast). The resulting data were averaged in 0.5-dbar bins and compared to similarly bin-averaged, processed CTD data. UCTD-CTD rms differences in all parameters increase as the descent rate falls below $1.5 \mathrm{dbar} \mathrm{s}^{-1}$ (Fig. 12). The fact that large UCTD-CTD differences in temperature and conductivity are observed at low descent rates suggests that the large salinity spikes exhibited in Fig. 2 result from an as-yet-unexplained effect (possibly a wake effect) and do not result from simple temperature/ conductivity alignment errors or thermal mass errors.

The effect of the UCTD data processing can be seen in Fig. 12, where rms differences in conductivity, salinity, and density for processed data are significantly lower than for raw data at descent rates greater than $1.5 \mathrm{dbar} \mathrm{s}^{-1}$. Table 2 shows that rms differences for processed UCTD data at descent rates exceeding $1.5 \mathrm{dbar} \mathrm{s}^{-1}$ are $4.5 \times 10^{-3}{ }^{\circ} \mathrm{C}$ for $T, 7.7 \times 10^{-4} \mathrm{~S} \mathrm{~m}^{-1}$ for $C, 7.3 \times 10^{-3}$ psu for $S$, and $5.8 \times$ $10^{-3} \mathrm{~kg} \mathrm{~m}^{-3}$ for $\sigma_{\theta}$. Assuming that the processed CTD data are error free, these estimates represent upper bounds for the accuracy of the UCTD data at descent rates in the range $1.5-2.5 \mathrm{dbar} \mathrm{s}^{-1}$. The conductivity and salinity differences are significantly lower than the nominal accuracy of the UCTD as specified by the manufacturer $(2-5 \times$ $10^{-3} \mathrm{~S} \mathrm{~m}^{-1}$ and $2-5 \times 10^{-2}$ psu for $C$ and $S$, respectively). Although we have demonstrated that viscous heating of the UCTD thermistor may be responsible for fluctuations 
TABLE 2. Accuracy of 0.5-dbar bin-averaged UCTD measurements relative to processed and similarly bin-averaged CTD (SBE 911) results averaged over all calibration casts. The rms differences are computed using only those pressure bins for which the descent rate exceeded $1.5 \mathrm{dbar} \mathrm{s}^{-1}$. For the case with processing, the thermal mass correction was performed using the Morison et al. (1994) velocitydependent parameters.

\begin{tabular}{lcccc}
\hline \hline UCTD calibration/processing & $\Delta T_{\text {rms }}\left({ }^{\circ} \mathrm{C}\right)$ & $\Delta C_{\mathrm{rms}}\left(\mathrm{S} \mathrm{m}^{-1}\right)$ & $\Delta S_{\mathrm{rms}}(\mathrm{psu})$ & $\Delta \sigma_{\mathrm{rms}}\left(\mathrm{kg} \mathrm{m}^{-3}\right)$ \\
\hline No calibration, no processing & $5.3 \times 10^{-3}$ & $1.3 \times 10^{-3}$ & $1.1 \times 10^{-2}$ & $8.5 \times 10^{-3}$ \\
Calibration, all processing & $4.5 \times 10^{-3}$ & $7.7 \times 10^{-4}$ & $7.3 \times 10^{-3}$ & $5.8 \times 10^{-3}$ \\
\hline
\end{tabular}

in salinity that are correlated with instrument descent rate, the viscous heating mechanism does not appear to be sufficient to explain all of the observed variability during instrument decelerations. It is possible that the estimate of the heating effect is in error. For example, we computed the viscous heating effect using the Larson and Pedersen (1996) result for a thermistor oriented perpendicular to the flow, which seems most consistent with the UCTD. However, even if the viscous heating effect is computed using the Larson and Pedersen (1996) result for a thermistor oriented parallel to the flow, which results in an approximately $60 \%$ larger temperature error, the salinity fluctuations associated with rapid instrument decelerations are still not totally accounted for. In fact, the occurrence of UCTD salinity spikes at low descent rates when deployed on a CTD rosette for the calibration casts, a situation where viscous heating is not important suggests an additional, as yet unknown, cause.

With the side-by-side UCTD-CTD comparisons showing increasing errors at descent rates less than $1.5 \mathrm{dbar} \mathrm{s}^{-1}$, and the fact that we observe salinity increases associated with rapid deceleration in UCTD free casts, it seems prudent to treat UCTD data obtained at speeds less than $1.5 \mathrm{dbars}^{-1}$ with caution. With free casts, only a small portion of the profile has a descent rate less than this threshold, but for tow-yo casts (e.g., see Fig. 1), elimination of data for descent rates less than $1.5 \mathrm{dbar} \mathrm{s}^{-1}$ would result in loss of a substantial portion of the profile.

\section{Summary and recommendations for processing}

We have presented in this paper an analysis and evaluation of underway CTD data with the objective of developing processing methodologies that will produce the highest accuracy salinities. The results will be applicable as well to other unpumped, rapidly profiling CTD systems. As previous investigators have concluded for other CTDs, we find it necessary to carefully align conductivity and temperature to account for differences in sensor response and in the physical location of the sensors. For the unpumped UCTD, the time shift of conductivity relative to temperature should be based on the local instrument descent rate. At low descent rate, the conductivity lags temperature and thus must be advanced relative to temperature, and at high descent rate, the reverse is true. Because the UCTD can profile at greater than $4 \mathrm{dbars}^{-1}$, the effect of viscous heating of the thermistor is nonnegligible and the temperature should be corrected for this effect prior to computing salinity. As has been found for other CTDs, the UCTD conductivity measurement is also subject to thermal mass errors. This effect is small at the high descent rate associated with UCTD free casts, but becomes more important as descent rates decrease, as occurs when the UCTD is deployed in tow-yo mode. Use of the correction methodology of Lueck and Picklo (1990) with parameters computed from the velocity-dependent functions of Morison et al. (1994) was shown to work well.

Our recommended processing methodology for UCTD data is as follows. Filter the raw temperature and conductivity with a cutoff period of four scans $(0.25 \mathrm{~s})$. Filter pressure and its time derivative (descent rate) with a cutoff period of 32 scans $(2 \mathrm{~s})$. Align temperature with conductivity by advancing or retarding temperature using the value from Fig. 5 for the local value of the instrument descent rate. Correct temperature for the effect of viscous heating using the results of Larson and Pedersen (1996) given by Eq. (8). Estimate the velocity through the conductivity cell using Eq. (3) and use that velocity to estimate the parameters for the thermal mass correction ( $\alpha$ and $\tau$ ) from the functions given by Morison et al. (1994). Use these parameters to correct the conductivity for the thermal mass error. The thermal mass error correction step can be omitted if the UCTD was deployed in free-cast mode. Finally, compute salinity with the corrected temperature and conductivity.

Acknowledgments. Funding for this project was provided by the National Science Foundation through Grant OCE1027573. We gratefully acknowledge Carol Janzen for helpful discussions regarding the processing of CTD data and for comments on an earlier version of this paper. Jochen Klinke provided us with helpful and timely troubleshooting of the UCTD while we were at sea. We thank James Fontaine for his work on the weatherproofing of the UCTD winch and line spooler. Thanks are also due to the captains and crews of the $\mathrm{R} / \mathrm{V}$ Knorr and R/V Endeavor for their assistance in obtaining the UCTD and CTD datasets in the difficult 
conditions encountered in the North Atlantic during winter.

\section{REFERENCES}

Barth, J. A., R. O'Malley, J. Fleischbein, R. L. Smith, and A. Huyer, 1996: SeaSoar and CTD observations during the Coastal Jet Separation cruise W9408A, August to September 1994. Reference 96-1, Tech. Rep. 162, College of Oceanic and Atmospheric Sciences, Oregon State University, $170 \mathrm{pp}$.

Furlong, A., G. Bugden, B. Beanlands, M. Eisan, K. Suguro, and Y. Namiki, 2000: Near vertical water column in-situ profiling with a Moving Vessel Profiler (MVP). Proc. Oceanology Int. 2000 Conf., Brighton, United Kingdom, Oceanology International, $10 \mathrm{pp}$.

Garau, B., S. Ruiz, W. G. Zhang, A. Pascual, E. Heslop, J. Kerfoot, and J. Tintore, 2011: Thermal lag correction on Slocum CTD glider data. J. Atmos. Oceanic Technol., 28, 1065-1071, doi:10.1175/JTECH-D-10-05030.1.

Gregg, M. C., and W. C. Hess, 1985: Dynamic response calibration of Sea-Bird temperature and conductivity probes. J. Atmos. Oceanic Technol., 2, 304-313, doi:10.1175/1520-0426(1985)002<0304: DRCOSB $>2.0 . \mathrm{CO} ; 2$.

Horne, E. P. W., and J. M. Toole, 1980: Sensor response mismatches and lag correction techniques for temperaturesalinity profilers. J. Phys. Oceanogr., 10, 1122-1130, doi:10.1175/ 1520-0485(1980)010<1122:SRMALC $>2.0 . C O ; 2$
Johnson, G. C., J. M. Toole, and N. G. Larson, 2007: Sensor corrections for Sea-Bird SBE-41CP and SBE-41 CTDs. J. Atmos. Oceanic Technol., 24, 1117-1130, doi:10.1175/JTECH2016.1.

Kundu, P. K., 1990: Fluid Mechanics. Academic Press, 638 pp.

Larson, N., and A. M. Pedersen, 1996: Temperature measurements in flowing water: Viscous heating of sensor tips. Proceedings of the First IGHEM Meeting, Montreal, QC, Canada, IGHEM. [Available online at http://www.seabird. com/technical_references/viscous.htm.]

Lueck, R. G., 1990: Thermal inertia of conductivity cells: Theory. J. Atmos. Oceanic Technol., 7, 741-755, doi:10.1175/ 1520-0426(1990)007<0741:TIOCCT>2.0.CO;2.

_, and J. J. Picklo, 1990: Thermal inertia of conductivity cells: Observations with a Sea-Bird cell. J. Atmos. Oceanic Technol., 7, 756768, doi:10.1175/1520-0426(1990)007<0756:TIOCCO > 2.0.CO;2.

Morison, J., R. Andersen, N. Larson, E. D'Asaro, and T. Boyd, 1994: The correction for thermal-lag effects in Sea-Bird CTD data. J. Atmos. Oceanic Technol., 11, 1151-1164, doi:10.1175/ 1520-0426(1994)011<1151:TCFTLE > 2.0.CO;2.

Perkin, R. G., and E. L. Lewis, 1982: Design of CTD observational programmes in relation to sensor time constants and sampling frequencies. Canadian Technical Report of Hydrography and Ocean Sciences 7, Institute of Ocean Sciences, Department of Fisheries and Oceans Canada, $47 \mathrm{pp}$.

Rudnick, D. L., and J. Klinke, 2007: The underway conductivitytemperature-depth instrument. J. Atmos. Oceanic Technol., 24, 1910-1923, doi:10.1175/JTECH2100.1. 